\title{
Model-Informed Development of Sotalol Loading and Dose Escalation Employing an Intravenous Infusion
}

\author{
John C. Somberg ${ }^{\mathrm{a}, \mathrm{c}}$, Alexander A. Vinks ${ }^{\mathrm{b}}$, Min Dong ${ }^{\mathrm{b}}$, Janos Molnar ${ }^{\mathrm{a}}$
}

\begin{abstract}
Background: Sotalol is often employed to prevent recurrence of symptomatic atrial flutter/atrial fibrillation. Because sotalol can prolong the QT interval excessively causing ventricular arrhythmias, a 3-day in-hospital loading or dose escalation period is mandated with oral administration in the product label for patient safety. In patients with normal renal function, 3 days (five oral doses) are required to obtain steady state maximum sotalol concentration, which results in maximum QT prolongation. The aim of this study is to develop an intravenous to oral loading regime for sotalol therapy that reduces the 3-day in-hospital initiation or dose escalation with oral administration to 1 day without compromising patient safety.
\end{abstract}

Methods: Using model-informed drug development techniques, simulations were developed for initiation and dose escalation of sotalol therapy by employing an intravenous loading dose followed by oral sotalol administrations.

Results: In patients with normal renal function, an initial 1-h loading dose of intravenous sotalol followed by two oral doses in $24 \mathrm{~h}$ has been developed permitting attainment of three maximum serum concentrations reflecting maximum QT prolongation in a 1-day observation period. Dosing regimens for patients with impaired renal function are also developed.

Conclusions: In patients with normal renal function, using an intravenous loading dose followed by oral administrations permits safe initiation or dose escalation of sotalol in 1 day instead of the 3-day dosing regimen with oral administration.

Keywords: Sotalol; Intravenous sotalol; Simulations; Dose initiation; Dose escalation

Manuscript submitted July 27, 2020, accepted August 3, 2020

Published online August 7, 2020

aAmerican Institute of Therapeutics, 21 N Skokie Hwy, Suite G-3, Lake Bluff, IL 60044, USA

bDivision of Clinical Pharmacology, Cincinnati Children's Hospital Medical Center, 3333 Burnet Avenue, MLC6018, Cincinnati, OH 45229, USA

${ }^{\mathrm{c} C}$ Corresponding Author: John C. Somberg, American Institute of Therapeutics, 21 N Skokie Hwy, Suite G-3, Lake Bluff, IL 60044, USA.

Email: jsomberg.api@comcast.net

doi: https://doi.org/10.14740/cr1143

\section{Introduction}

Sotalol is a frequently employed therapy to prevent the recurrence of very symptomatic atrial fibrillation (AF), or atrial flutter (AFL) $[1,2]$. Because sotalol can prolong the QTc interval excessively $[3,4]$ and thus may lead to the initiation of torsades de pointes (TdP) ventricular tachycardia (VT) [3-5], initiation of sotalol therapy has been recommended in the product label to be in-hospital under electrocardiogram (ECG) monitoring with facilities and personnel able to provide cardiac resuscitation [4]. Given the half-life of sotalol being on average $10-12 \mathrm{~h}, 3$ hospital days are needed to reach a steady state (Cmax) blood concentration of sotalol. The blood concentration of sotalol directly relates to the prolongation in the QTc interval and thus proarrhythmia risk [3,4]. The peak blood concentration reached at the steady state (Cmax ss) is the highest concentration and thus offers greatest risk. Three hospital days in a telemetry bed is a considerable expenditure of time and resources for the loading of sotalol. The economic cost is considerable and has been estimated at \$9,263 (CMS reimbursement for 3-day initiation of sotalol) [6]. In addition to cost, there is the allocation of resources and the increased exposure of patient to nosocomial acquisition of infections. We hypothesize that intravenous (IV) loading of sotalol followed by oral dosing in quick successions could achieve a sotalol blood concentration similar to that achieved with chronic oral dosing. In this way, a patient under ECG observation could be evaluated as to the QTc response to peak blood sotalol level, and from that the QTc effect could be determined and thus the extent of risk of sotalol therapy would be anticipated. The IV sotalol load followed by the first and second oral dose could be administered in $24 \mathrm{~h}$ with risk assessed under ECG monitoring in appropriate hospital facilities. This would shorten hospitalization, reduce patient inconvenience, reduce cost and reduce unneeded hospital exposure of the patient.

\section{Materials and Methods}

This is a modeling study using previously published data. The published data had the Institutional Review Board (IRB) approval, which is not needed for this study.

We initially approached the problem of 1-day IV and oral loading of sotalol with a proposed study to the Food and Drug Administration (FDA). In consultation with the Cardio Renal 
Table 1. Recommended Loading Dosages for Initiation and Dose Escalation of Sotalol Administration

\begin{tabular}{|c|c|c|c|c|c|c|}
\hline \multirow{3}{*}{$\mathrm{ClCr}^{\mathrm{a}}(\mathrm{mL} / \mathrm{min})$} & \multicolumn{4}{|c|}{$\begin{array}{l}\text { IV loading dose (mg) to be administered over } \\
1 \mathrm{~h} \text { when the oral dose is going from }\end{array}$} & \multirow{3}{*}{$\begin{array}{l}\text { Minimum delay to } \\
\text { first oral dose (h) }\end{array}$} & \multirow{3}{*}{$\begin{array}{l}\text { Oral dosing } \\
\text { interval (h) }\end{array}$} \\
\hline & \multicolumn{2}{|c|}{ Sotalol initiation } & \multicolumn{2}{|c|}{ Sotalol escalation } & & \\
\hline & $0-80 \mathrm{mg}^{\mathrm{b}}$ & 0 - $120 \mathrm{mg}$ & 80 - $120 \mathrm{mg}$ & 120 - $160 \mathrm{mg}$ & & \\
\hline$>90$ & 60 & 90 & 75 & 90 & 4 & 12 \\
\hline $60-90$ & 82.5 & 125 & 82.5 & 105 & 4 & 12 \\
\hline
\end{tabular}

${ }^{a}$ Calculated using Cockcroft-Gault formula. ${ }^{\mathrm{b}}$ Recommended starting dose. CICr: creatinine clearance; IV: intravenous.

Division of FDA, development was proposed along the lines of initiating a model-informed drug development (MIDD) pathway.

A previously performed bioequivalence study in 15 healthy volunteers aged 18 to 45 years old who received a single dose of oral and IV sotalol (crossover study) was employed to obtain serum sotalol concentration and corresponding QTc measurements [7]. A software package NONMEM ${ }^{\mathrm{TM}}$ version 7.2 (ICON, Hanover, MD, USA) was used for population pharmacokinetic (PK) modeling and simulation. First order conditional estimation method with interaction (FOCE-INTER) was used for computation. The R Foundation for Statistical Compiling was used for data preparation, graphical analysis, linear regression analysis and statistical analysis and summaries.

A detailed publication of the modeling methodologies are reported elsewhere [8]. A joint population pharmacokinetic/ pharmacodynamic (PK-PD) model with covariance between PK and PD parameters was employed. Models were evaluated for best fit by goodness-of-fit diagnostic plots, condition number and decrease in objective fraction value. The performance of the population PK-PD models was further evaluated using "boot strap" analysis and predictive check. The development population PK-PD model was utilized for simulations to determine IV loading doses of sotalol that matched with targeted Cmax ss levels associated with the oral (PO) dosing regimen of 80, 120 and $160 \mathrm{mg}$ PO twice a day (bid). These principles were applied to develop dose loading and dose escalation parameters, as well as modification of dose loading and escalation for patients with different degrees of renal function.

While innumerable possibilities exist as to the IV loading of sotalol followed by oral drug administration, we chose to administer the IV load over $1 \mathrm{~h}$ to Cmax ss target, to facilitate physicians following QTc changes from baseline every $15 \mathrm{~min}$, as well as evaluating changes in heart rate (HR) and blood pressure (BP) over a convenient time period. We next hypothesized that an oral sotalol dose should follow the infusion at such a time as to bring the sotalol blood level back to Cmax ss. The first oral dose would then be followed by a second oral dose at a pre-determined interval once again bringing the sotalol blood level back to Cmax ss. We planned that in 24 $\mathrm{h}$ or less, three Cmax ss concentrations of sotalol levels would be obtained to evaluate the drug's effect on QT interval. We expected that some patients would show excess QTc prolongation $(500 \mathrm{~ms}$ or greater, or a $20 \%$ increment in the QTc from baseline) such that dosing would need to be reduced, or sotalol therapy abandoned for alternative therapy.

\section{Results}

Modeling the parameters for 1-h IV infusion to target Cmax ss we obtained an infusion dose of sotalol based on the oral dosing schedule (Table 1). For $80 \mathrm{mg}$ PO bid oral dosing, one would administer $60 \mathrm{mg}$ to achieve an average Cmax ss target of 800 $\mathrm{ng} / \mathrm{mL}$, followed by $5 \mathrm{~h}$ from start of infusion of $80 \mathrm{mg}$ taken orally and then $12 \mathrm{~h}$ after the first oral dose another $80 \mathrm{mg}$ (17 $\mathrm{h}$ from start of infusion). Each oral dose will peak in $2-4 \mathrm{~h}$ following administration, permitting a check of HR, BP and QTc effects. Thus in a $21 \mathrm{~h}$ period, one has three sotalol peak concentrations that permits evaluation of QTc response and thus possible proarrhythmia. The simulation for loading to $80 \mathrm{mg}$ PO bid is depicted in Figure 1. Loading to $120 \mathrm{mg}$ sotalol bid dosing in patients with normal renal function is noted in Figure 2.

Since sotalol is known to be mostly excreted by the kidney unchanged [9] and elimination is directly proportional to glomerular filtration [10], we developed based on modeling and simulation technique, doses to obtain predicted Cmax for patients with mild, moderate and severe renal dysfunction. Proposed dosing is listed in Table 1 and simulations are depicted in Figures 3 and 4. Sotalol administration in patients with severe renal function was limited in the label to patients with a history of life-threatening VT.

In addition to loading there is the need for dose escalation. Patient may be on oral sotalol $80 \mathrm{mg}$ PO bid or $120 \mathrm{mg}$ PO bid and because of breakthrough atrial fibrillation, escalation to the next higher dose may be desired to accomplish achieving a higher concentration. Simulations were created to escalate from $80 \mathrm{mg}$ to $120 \mathrm{mg}$ bid or $120 \mathrm{mg}$ to $160 \mathrm{mg}$ in 1 day using IV loading. The initial IV load for escalation is listed in Table 1. Simulations for 1-day dose escalation are presented in Figures 5 and 6 for the two dose escalations, for patients with normal renal function. Patient with impaired renal function can also undergo dose escalation with doses given for initial IV loading and then times to first and second oral doses (Table 1). Simulations are presented for dose escalation in patients with mild, moderate and severe renal function (Fig. 7).

A patient could be initiated with a loading dose to $120 \mathrm{mg}$ PO bid (Cmax target), exhibit excessive QTc prolongation and 


\section{- Without loading dose Loading + Maintenance dose}

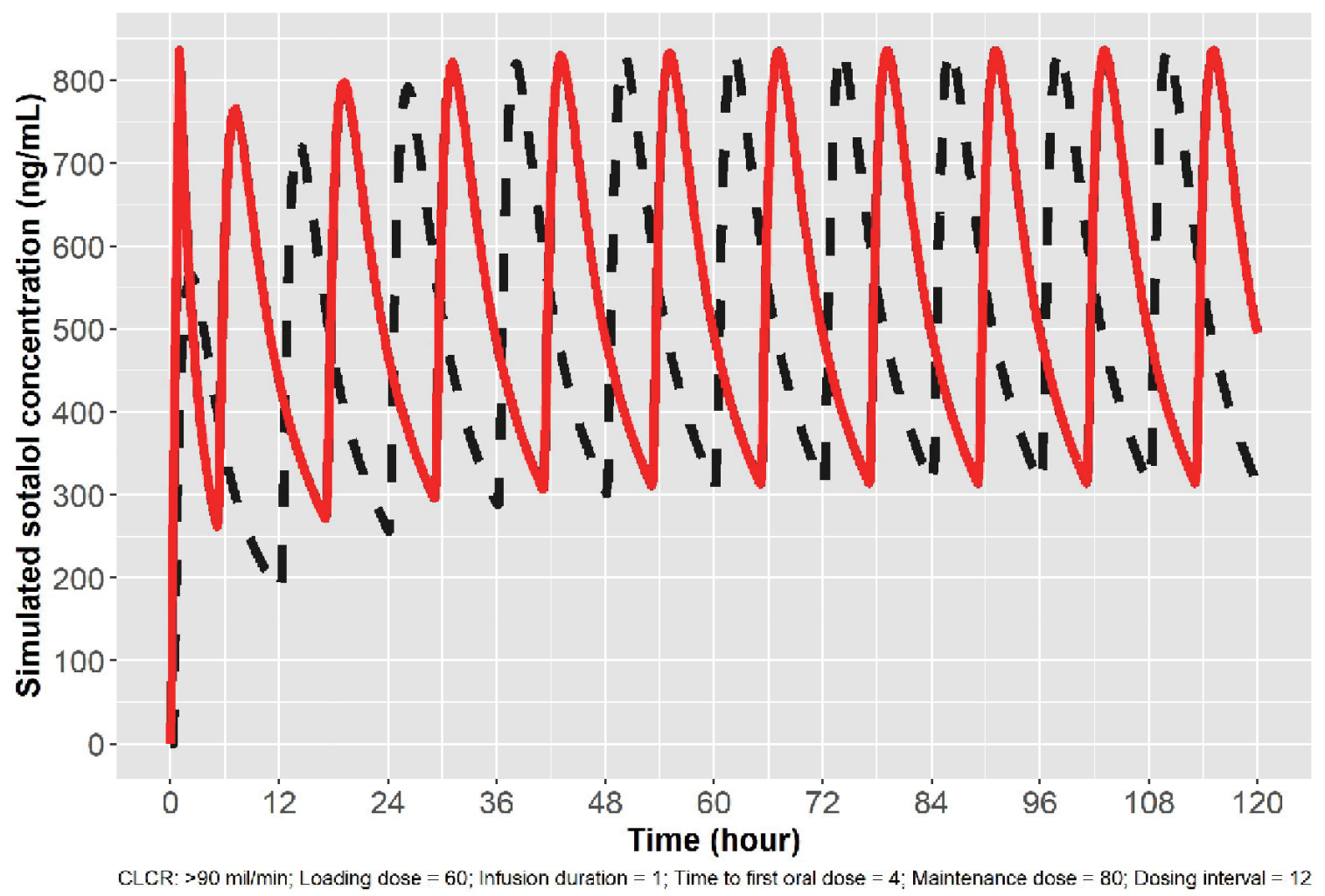

Figure 1. Simulation for $80 \mathrm{mg}$ loading in patients with normal renal function $(\mathrm{CICr}>90 \mathrm{~mL} / \mathrm{min})$. The broken line indicates sotalol concentrations with oral (PO) dosing. The solid line indicates sotalol concentrations following IV loading, and Cmax ss concentration can be obtained in $1 \mathrm{~h}$ and three Cmax peaks in $24 \mathrm{~h}$. IV: intravenous; CICr: creatinine clearance.

thus be placed on a lower dose of $80 \mathrm{mg}$ twice daily. Using modeling and simulation to guide re-initiation of sotalol at a lower dose of $80 \mathrm{mg}$ PO bid could be obtained by waiting 1 day (in patients with creatinine clearance $(\mathrm{ClCr})>60 \mathrm{~mL} / \mathrm{min})$, or at least 3 days in patients with $\mathrm{ClCr}<60$ or $\geq 30 \mathrm{~mL} / \mathrm{min}$, or 7 days in patients with $\mathrm{ClCr}<30$, but $\geq 15 \mathrm{~mL} / \mathrm{min}$. Simulations for dose "fall back" strategy are depicted in Figures 8 and 9.

\section{Discussion}

Employing model-informed drug development approaches, simulations were developed to employ IV sotalol infusion over $1 \mathrm{~h}$ to initially load patients who are to receive oral sotalol therapy to prevent recurrence of highly symptomatic AF/AFL. Since sotalol can prolong the QTc and excessive prolongation may lead to TdP VT in 3\% of patients [11], early determination of the QTc effect at maximum blood concentrations of sotalol (Cmax) is requisite to avoid proarrhythmic risk. Sotalol blood concentration is known to be directly proportional to the QTc prolongation $[11,12]$. Testing the Cmax that is seen with chronic oral therapy with a 1 -h infusion of IV sotalol permits a rapid evaluation of proarrhythmic risk, as well as HR and BP effects. With the first and second oral doses, a second and third sotalol concentration peak is achieved that further permits evaluation of the QTc effects in-hospital under careful monitoring, permitting appropriate dose reduction or therapy termination. While there is little evidence suggesting a delay in the QTc prolonging effects of sotalol, a hysteresis effect may occur in some patients, which would be observed following the second or third doses. That the effects of the greatest future sotalol blood concentration that will be obtained on oral dosing can be observed three times in patients with normal renal function in a $24 \mathrm{~h}$ period, provides assurance as to the safety of the selected oral dosing of sotalol for chronic oral therapy.

One can take the time concentration sotalol curves and transform them directly into a time QTc prolongation curve in QT variance $[3,4,11,12]$. However, this represents the average response. Certain patients may exhibit an exaggerated response with a given QTc prolongation being considerably longer than the mean response. These patients may be at the greatest risk for proarrhythmia. The exaggerated response may be due to potassium channel abnormalities. However, one must be cautious in that non-excessive QT prolongation can still lead to significant proarrhythmia in patients with hypokalemia, severe bradycardia, and extensive myocardial disease that are associated with a low ejection fraction.

While there was reluctance on the part of regulators to 


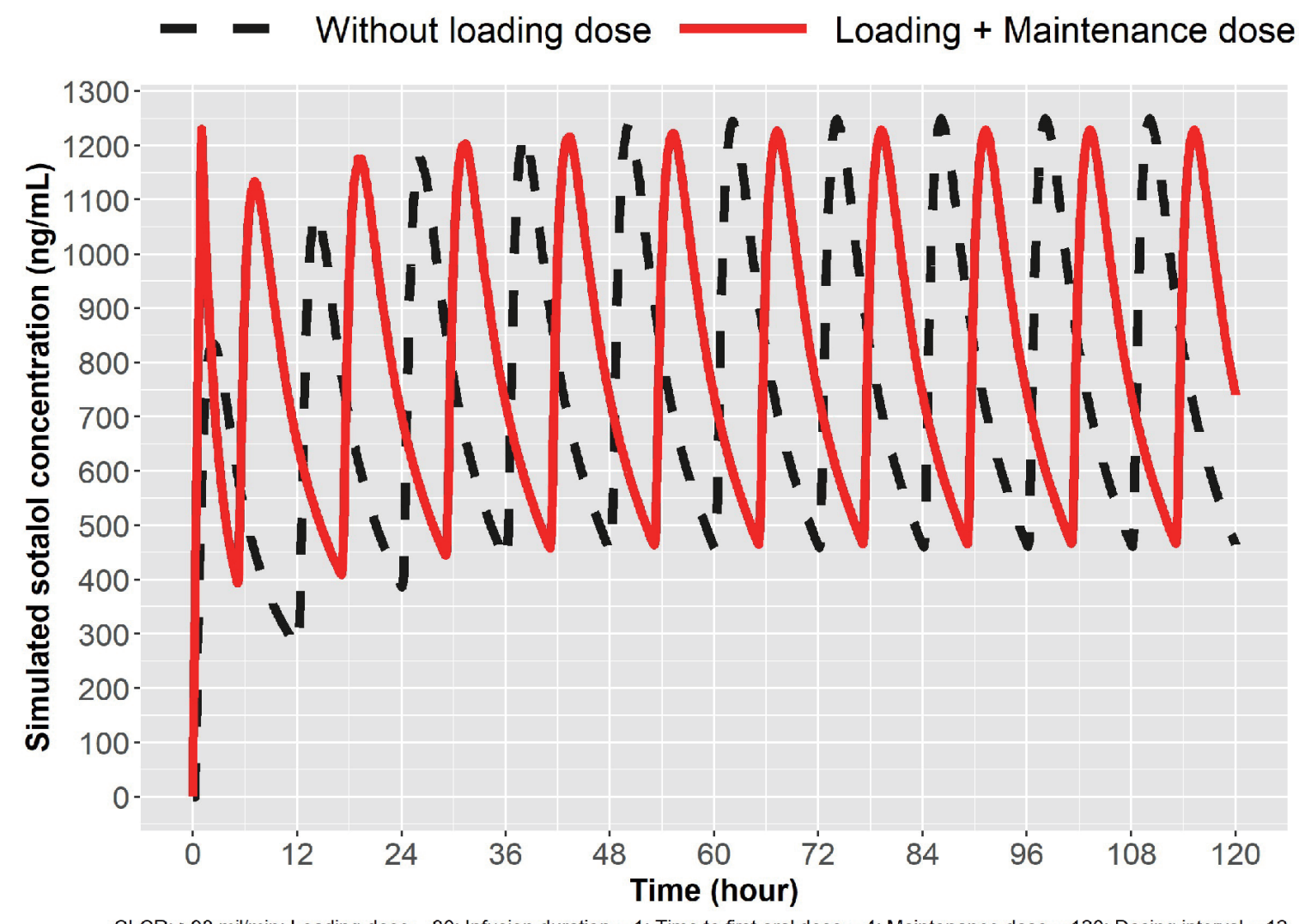

CLCR: >90 $\mathrm{mil} / \mathrm{min}$; Loading dose $=90 ;$ Infusion duration $=1 ;$ Time to first oral dose $=4 ;$ Maintenance dose $=120 ;$ Dosing interval $=12$

Figure 2. Simulation for $120 \mathrm{mg}$ loading in patients with normal renal function ( $\mathrm{ClCr}>90 \mathrm{~mL} / \mathrm{min})$. Oral dosing $120 \mathrm{mg}$ sotalol every $12 \mathrm{~h}$ (broken line) and IV loading $90 \mathrm{mg}$ over $1 \mathrm{~h}$ followed by oral dosing. Cmax ss was obtained in $1 \mathrm{~h}$ with IV loading. IV: intravenous; CICr: creatinine clearance.

provide for loading to $120 \mathrm{mg}$ initially, having both regimens available to initiate sotalol, offers considerable advantage. Many physicians chose to start with $120 \mathrm{mg}$ PO bid, since this dose has the greatest likelihood of maintaining sinus rhythm [13]. Having this option for initial oral loading will facilitate adoption of the IV sotalol loading strategy.

The model revealed that patients with mild, moderate and severe renal dysfunction have an average higher maximum serum sotalol concentration than patients with normal renal function, despite adjustments in dosing based on $\mathrm{ClCr}$. Because of these higher concentrations, a larger loading dose of sotalol is required in these groups to assess the QTc response to a higher concentration of sotalol with chronic oral therapy. If physicians want to have their patients with reduced renal function receive a reduced maximum sotalol serum concentrations, then a lower maintenance dose of sotalol should be selected. When a lower chronic dose is selected, then a reduced "test" IV dose can be employed. It is the target dosing that dictates the concentration of the initial IV loading.

\section{Conclusions}

Using pharmacokinetic modeling, the loading and dose escala- tion schedules were developed for patients who are to receive chronic oral sotalol. Dosing regimens were adjusted for renal function. Patient in-hospital evaluation could be accomplished in $24 \mathrm{~h}$ in patients with normal renal function.

\section{Acknowledgments}

Authors thank to Issam Zineh, PharmD, MPH, Norman Stockbridge, $\mathrm{MD}, \mathrm{PhD}$, and their associates at the FDA: Karen Hicks, MD, Charu Gandotra, MD, Ramana Uppoor, PhD, Sudharshan Hariharan, $\mathrm{PhD}$, Girish Bende, $\mathrm{PhD}$, Yaning Wang, $\mathrm{PhD}$, Hao Zhu, PhD, Chao Liu, PhD, Luning (Ada) Zhuang, PhD, Rajnikanth Madabushi, PhD, Sharonjit Sagoo, PharmD, CPH, David Strauss, MD, PhD, Renmeet Grewal, PharmD, MS, Jessica Benjamin, MPH, Tracey Lee, BS, RN, MSN, Yvonne Knight, MS, Christopher Egelebo, Million Tegenge, $\mathrm{PhD}$, Jacqueline Glen, MSc, Vivianna Cowl, Ququan Liu MD, MS, for their guidance and model modification.

\section{Financial Disclosure}

This work has been sponsored by AltaThera Pharmaceuticals, 
- Without loading dose Loading + Maintenance dose

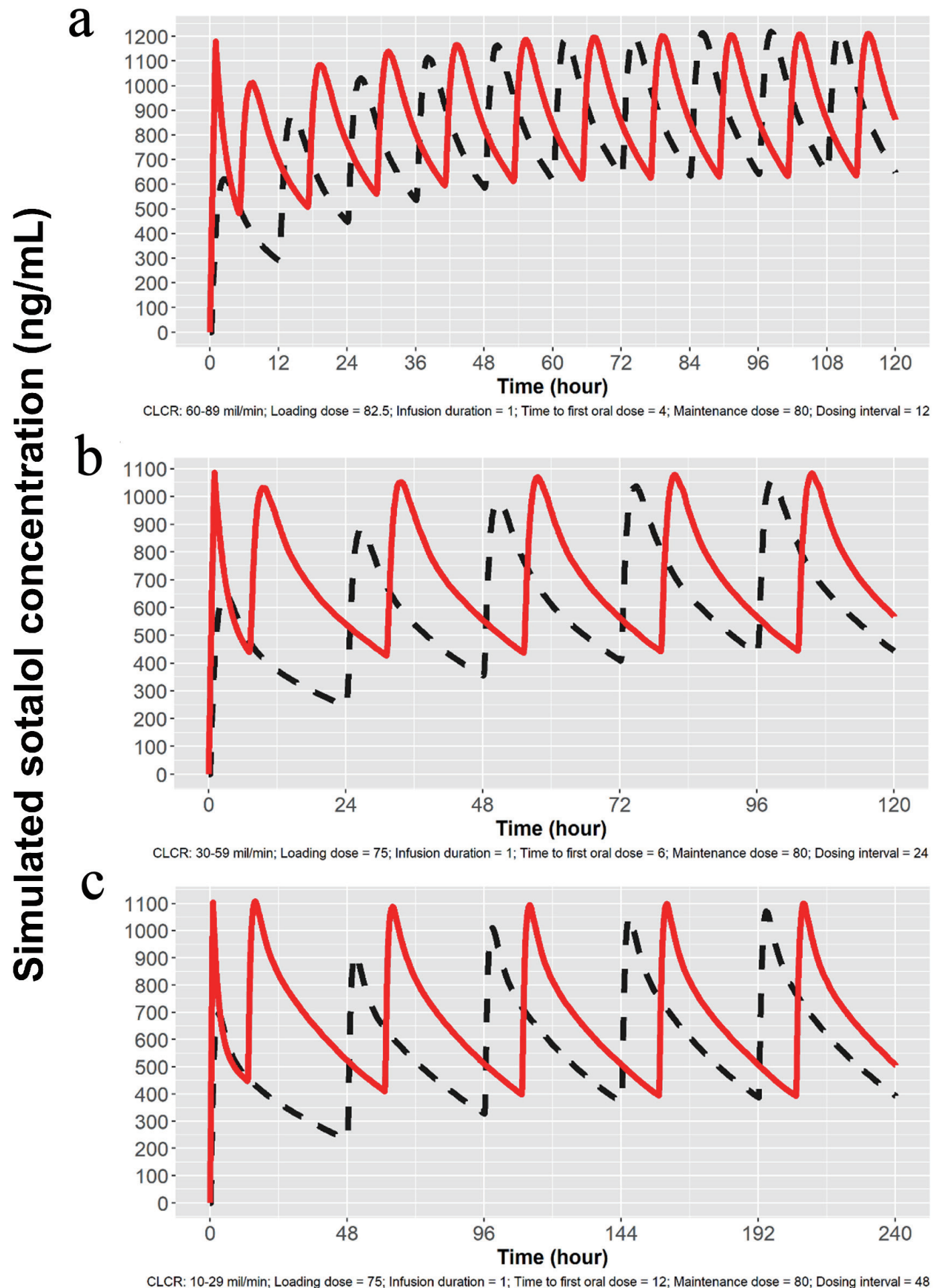

Figure 3. Simulations for $80 \mathrm{mg}$ dosing for patients with mild, moderate and severe renal impairment. (a) Simulation with mild renal impairment (CICr: $60-89 \mathrm{~mL} / \mathrm{min}$ ). Oral loading broken lines and solid line with $82.5 \mathrm{mg}$ IV load. (b) Simulation for moderate renal impairment ( $\mathrm{ClCr}$ : $30-59 \mathrm{~mL} / \mathrm{min})$. Broken line indicates oral loading and solid line $75 \mathrm{mg} I V$ load, followed by $80 \mathrm{mg} P O$ at $7 \mathrm{~h}$ and then $80 \mathrm{mg} \mathrm{PO}$ every $24 \mathrm{~h}$. (c) Simulation for severe renal impairment (CICr: $10-29 \mathrm{~mL} / \mathrm{min}$ ). Broken line indicates oral loading $80 \mathrm{mg}$ PO every $48 \mathrm{~h}$, while solid line represents $75 \mathrm{mg} \mathrm{IV}$ followed by $80 \mathrm{mg} \mathrm{PO}$ at $13 \mathrm{~h}$ and then every $48 \mathrm{~h}$ thereafter. IV: intravenous; CICr: creatinine clearance; PO: oral. 


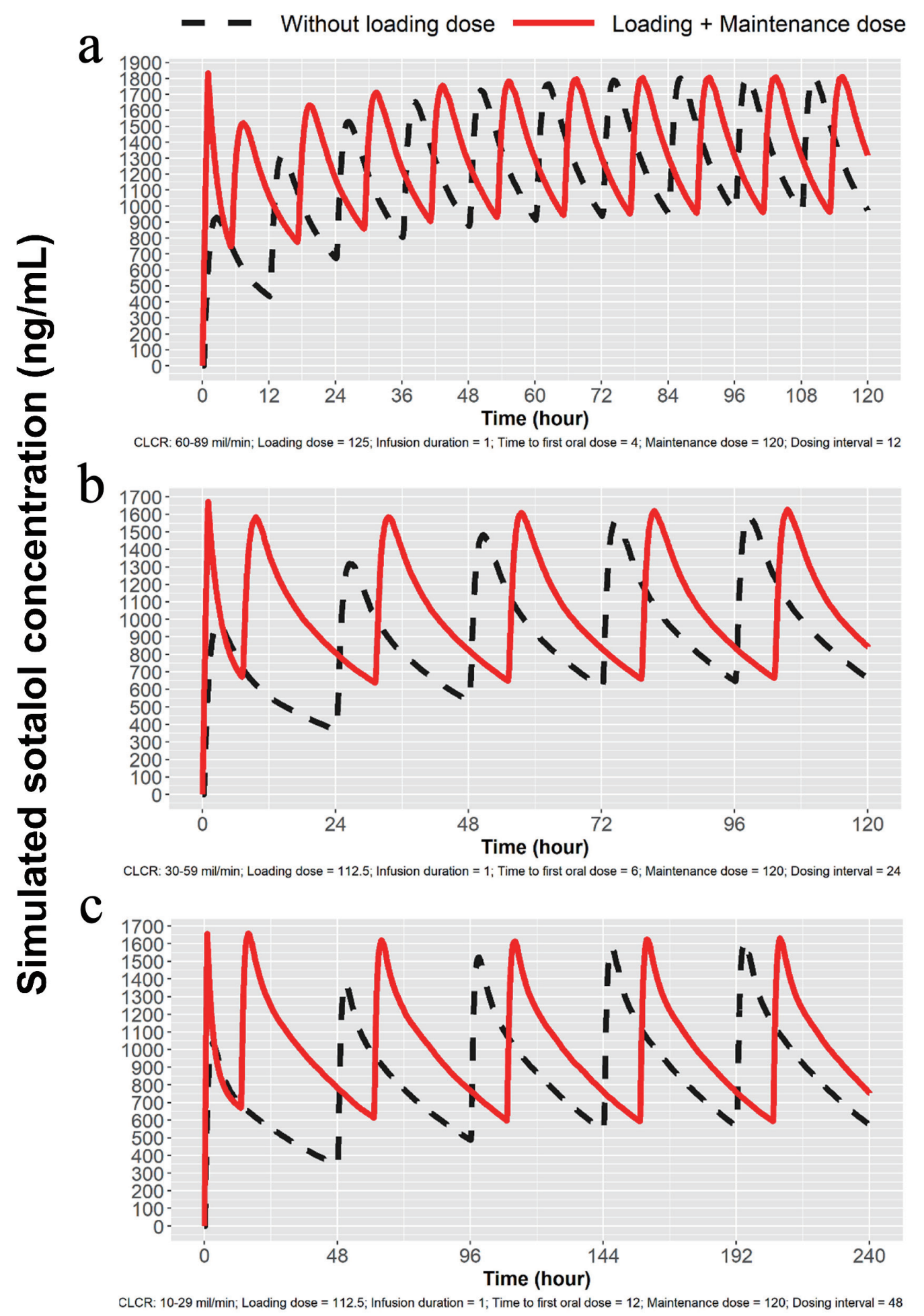

Figure 4. Simulations for $120 \mathrm{mg}$ dosing for patients with mild, moderate and severe renal impairment. (a) Simulation for mild renal impairment (CICr: $60-89 \mathrm{~mL} / \mathrm{min})$. Broken line represents $120 \mathrm{mg}$ sotalol PO every $12 \mathrm{~h}$ and the solid line represents 125 $\mathrm{mg}$ IV load over $1 \mathrm{~h}$ followed by $120 \mathrm{mg}$ at $5 \mathrm{~h} \mathrm{PO}$ and then every $12 \mathrm{~h}$ thereafter. (b) Simulation for moderate renal impairment (CICr: $30-59 \mathrm{~mL} / \mathrm{min}$ ). Broken line represents $120 \mathrm{mg}$ sotalol PO administered every $24 \mathrm{~h}$ and solid line represents $112.5 \mathrm{mg}$ IV over $1 \mathrm{~h}$ followed by $120 \mathrm{mg}$ at $7 \mathrm{~h}$ and then $120 \mathrm{mg}$ PO every $24 \mathrm{~h}$. (c) Simulation for severe renal impairment (CICr: $10-29 \mathrm{~mL} /$ $\mathrm{min}$ ). Broken line represents $120 \mathrm{mg}$ sotalol orally every $48 \mathrm{~h}$ and the solid line $112.5 \mathrm{mg}$ IV over $1 \mathrm{~h}$ followed by $120 \mathrm{mg}$ orally at $13 \mathrm{~h}$ and then $120 \mathrm{mg}$ PO every $48 \mathrm{~h}$. IV: intravenous; CICr: creatinine clearance; PO: oral. 


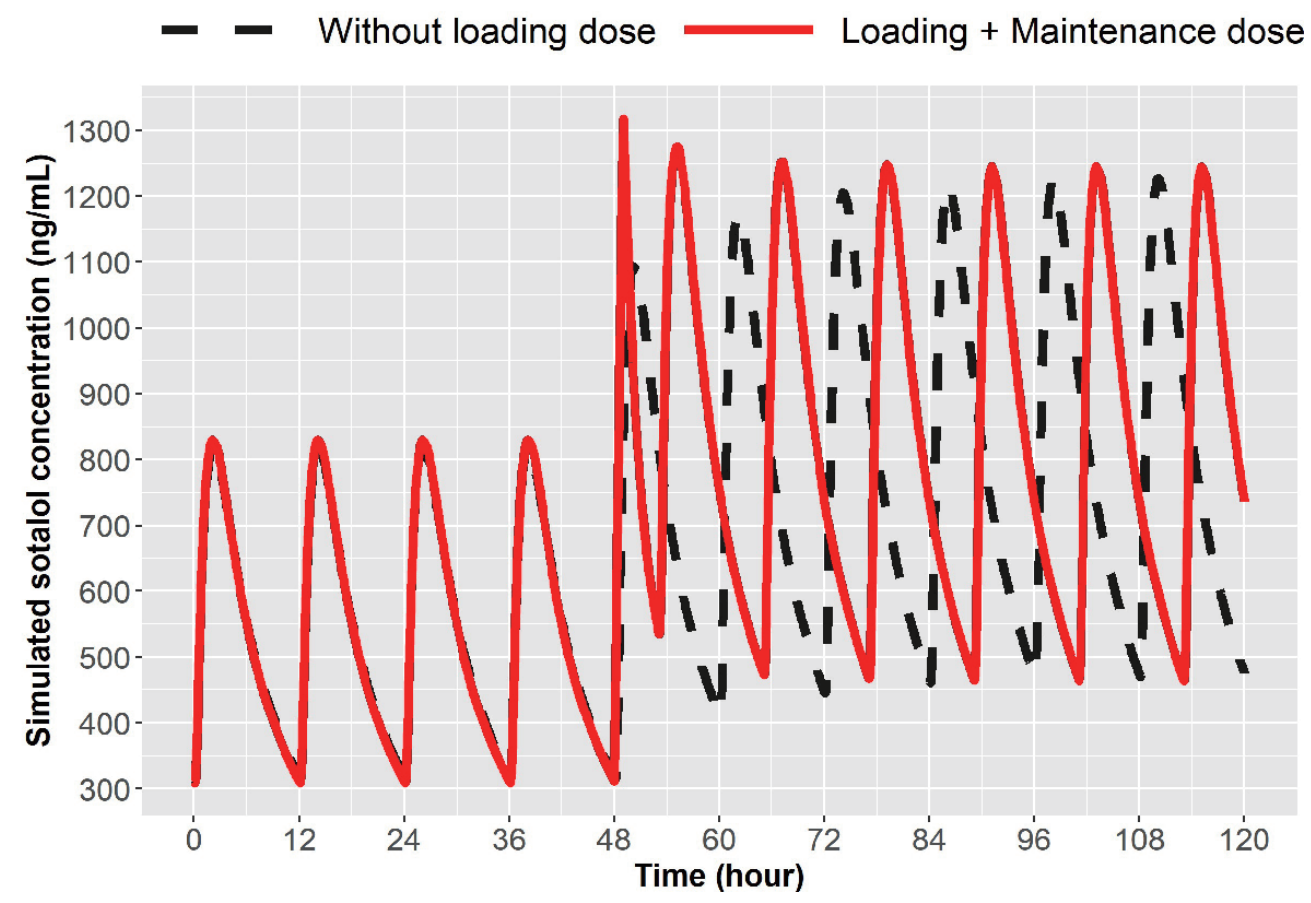

Figure 5. Simulation for dose escalation from 80 to $120 \mathrm{mg}$ in patients with normal renal function ( $\mathrm{ClCr}>90 \mathrm{~mL} / \mathrm{min}$ ). Broken line represents oral loading, $120 \mathrm{mg}$ every $12 \mathrm{~h}$ and the solid line represents $75 \mathrm{mg} \mathrm{IV}$ over $1 \mathrm{~h}$ given at $12 \mathrm{~h}$ after the last 80 $\mathrm{mg}$ PO dose followed by $120 \mathrm{mg}$ oral at $5 \mathrm{~h}$ and then every $12 \mathrm{~h}$ thereafter. IV: intravenous; CICr: creatinine clearance; PO: oral.

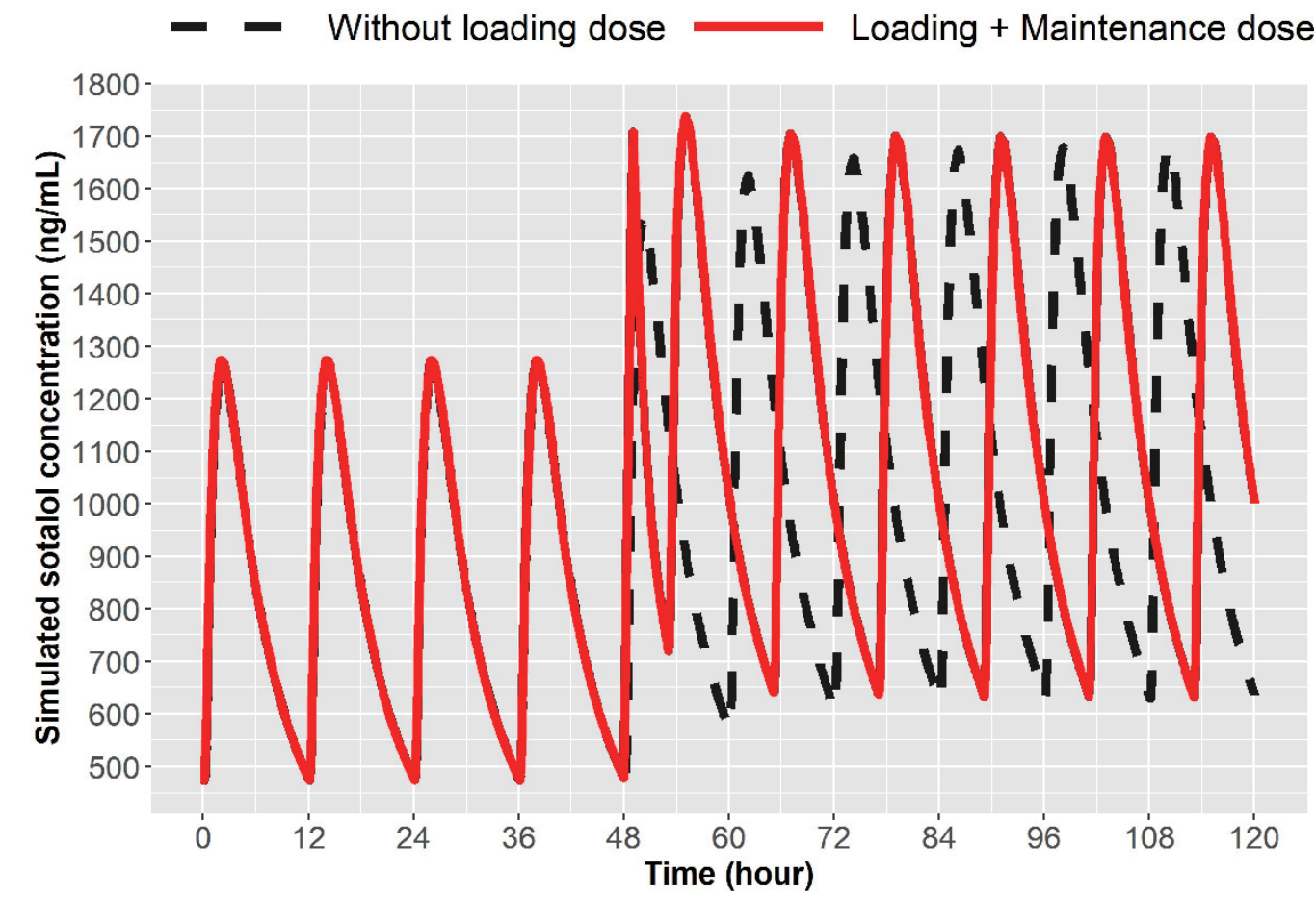

Figure 6. Simulation for dose escalation from 120 to $160 \mathrm{mg}$ in patients with normal renal function $(\mathrm{ClCr}>90 \mathrm{~mL} / \mathrm{min})$. The broken line represents $160 \mathrm{mg}$ PO sotalol $12 \mathrm{~h}$ after the last $120 \mathrm{mg}$ PO dose and then $160 \mathrm{mg}$ at every $12 \mathrm{~h}$ thereafter. The solid line represents $90 \mathrm{mg}$ IV sotalol loading over $1 \mathrm{~h}$ given $12 \mathrm{~h}$ after the last $120 \mathrm{mg}$ dose followed by $160 \mathrm{mg} \mathrm{PO}$ at $5 \mathrm{~h}$ and then every $12 \mathrm{~h}$ thereafter. IV: intravenous; CICr: creatinine clearance; PO: oral. 

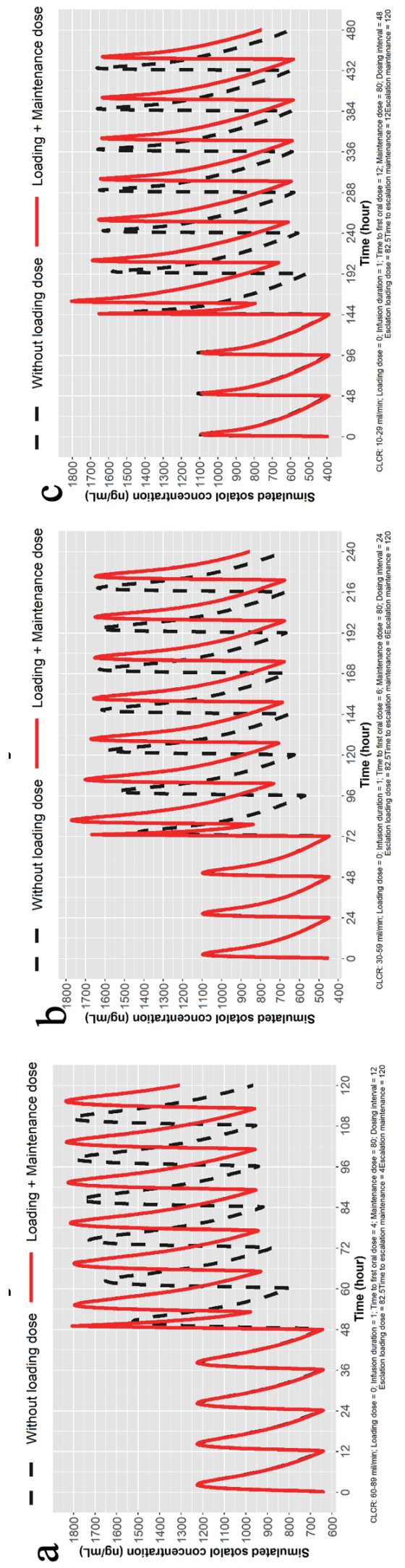

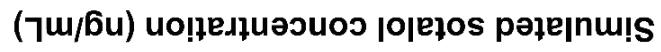
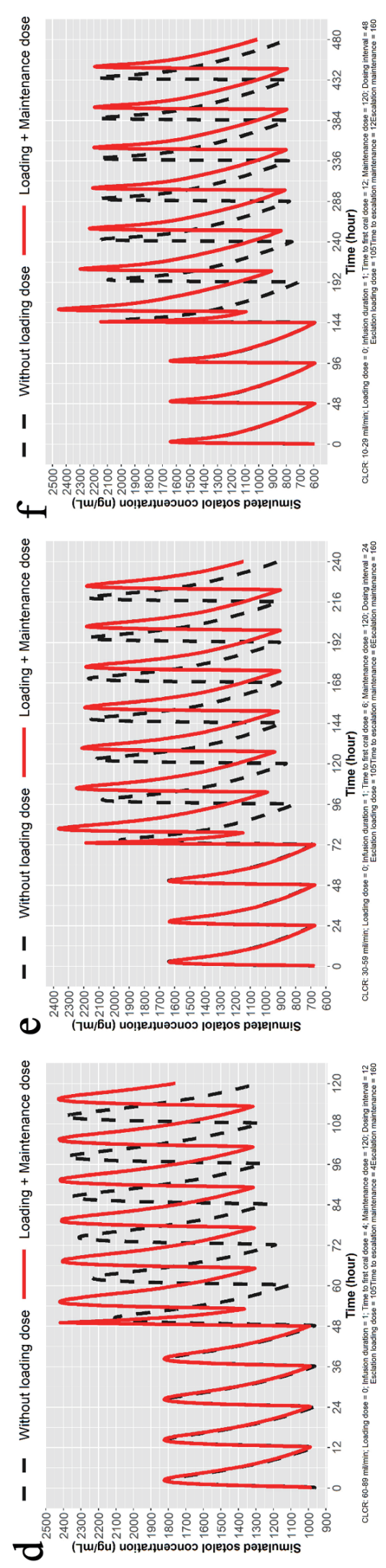

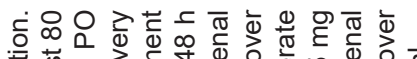

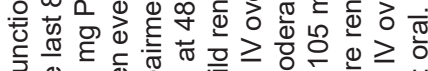

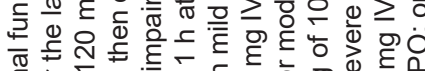

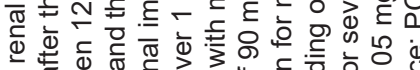

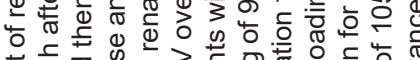

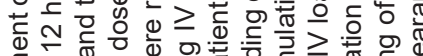

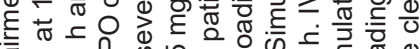

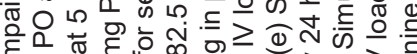

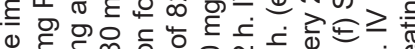

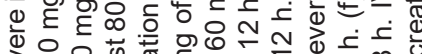

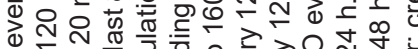
क

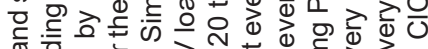

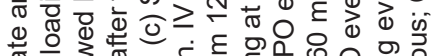
需 은

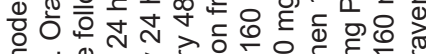

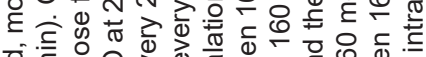
它产员

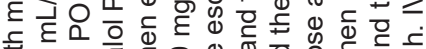

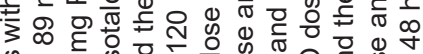

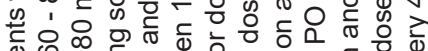

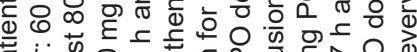

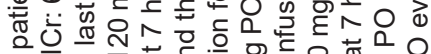

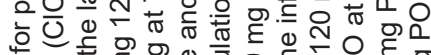
O

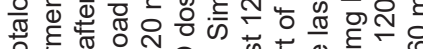
品些要

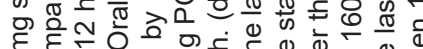

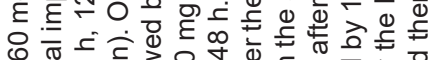

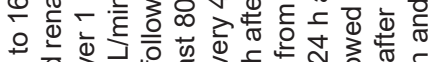

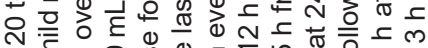

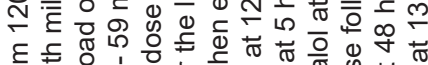

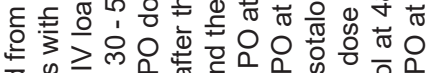

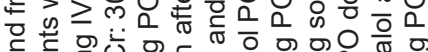

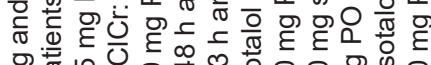

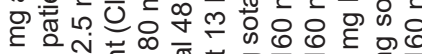

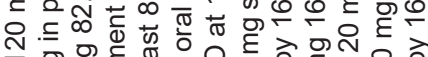

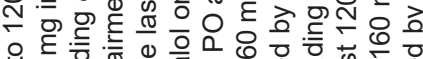

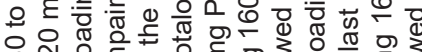

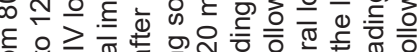
은

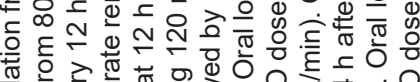
중

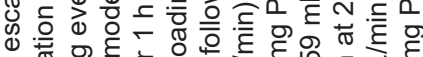

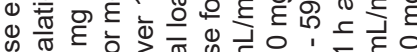
ه ర

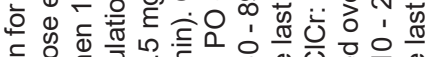

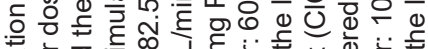

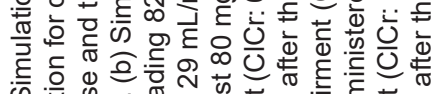
के

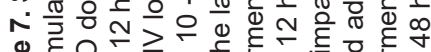

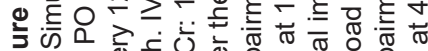

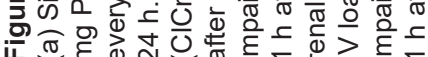




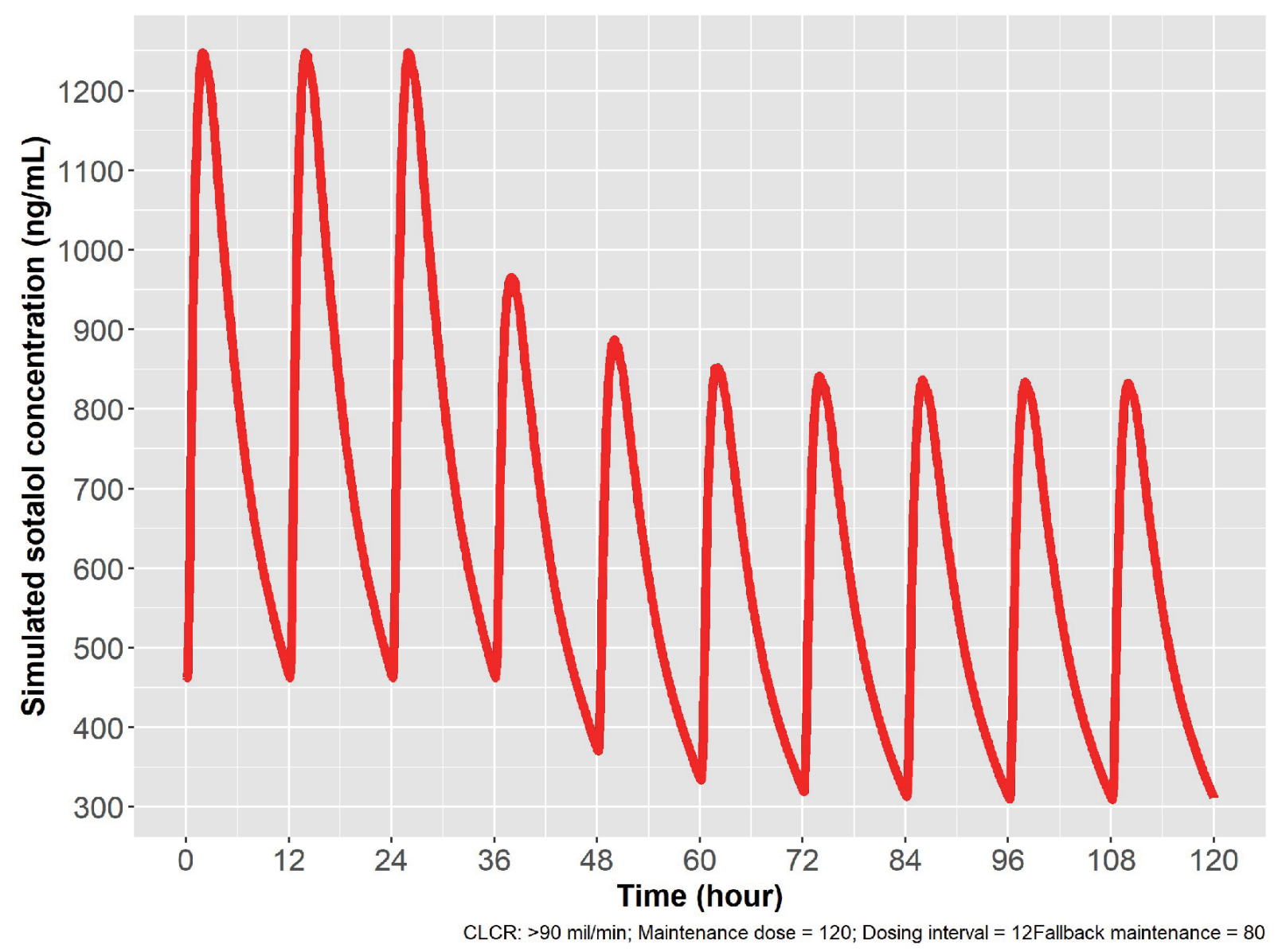

Figure 8. Simulation for dose reduction from 120 to $80 \mathrm{mg} \mathrm{PO}$ sotalol in patients with normal renal function (ClCr: $90 \mathrm{~mL} / \mathrm{min})$. After $12 \mathrm{~h}$ from the last $120 \mathrm{mg}$ dose, $80 \mathrm{mg}$ PO given with a new steady state achieved in $24 \mathrm{~h}$, with $80 \mathrm{mg}$ given every $12 \mathrm{~h}$. $\mathrm{CICr}$ : creatinine clearance; PO: oral.

Chicago, IL, USA.

\section{Conflict of Interest}

JCS developed IV sotalol and licensed it to AltaThera Pharmaceuticals. AAV: paid consultant to AltaThera Pharmaceuticals. MD: paid consultant to AltaThera Pharmaceuticals. JCS and JM have a patent that has been assigned to the sponsoring company, AltaThera Pharmaceuticals.

\section{Informed Consent}

This is a modeling study working from previously published data. There is no need for informed consent in this paper. The published papers previously mentioned informed consent.

\section{Author Contributions}

All authors contributed to the writing of this paper.

\section{Data Availability}

The data supporting the findings of this study are available in the published literature cited in this study.

\section{References}

1. January CT, Wann LS, Alpert JS, Calkins H, Cigarroa JE, Cleveland JC, Jr., Conti JB, et al. 2014 AHA/ACC/ HRS guideline for the management of patients with atrial fibrillation: a report of the American College of Cardiology/American Heart Association Task Force on practice guidelines and the Heart Rhythm Society. Circulation. 2014;130(23):e199-267.

2. The Top 300 Drugs of 2020. Available at: https://clincalc. com/DrugStats/Top300Drugs.aspx.

3. Soyka LF, Wirtz C, Spangenberg RB. Clinical safety profile of sotalol in patients with arrhythmias. Am J Cardiol. 1990;65(2):74A-81A; discussion 82A-83A.

4. Sotalol hydrochloride injection. Prescribing Information. Available at: https://dailymed.nlm.nih.gov/daily- 


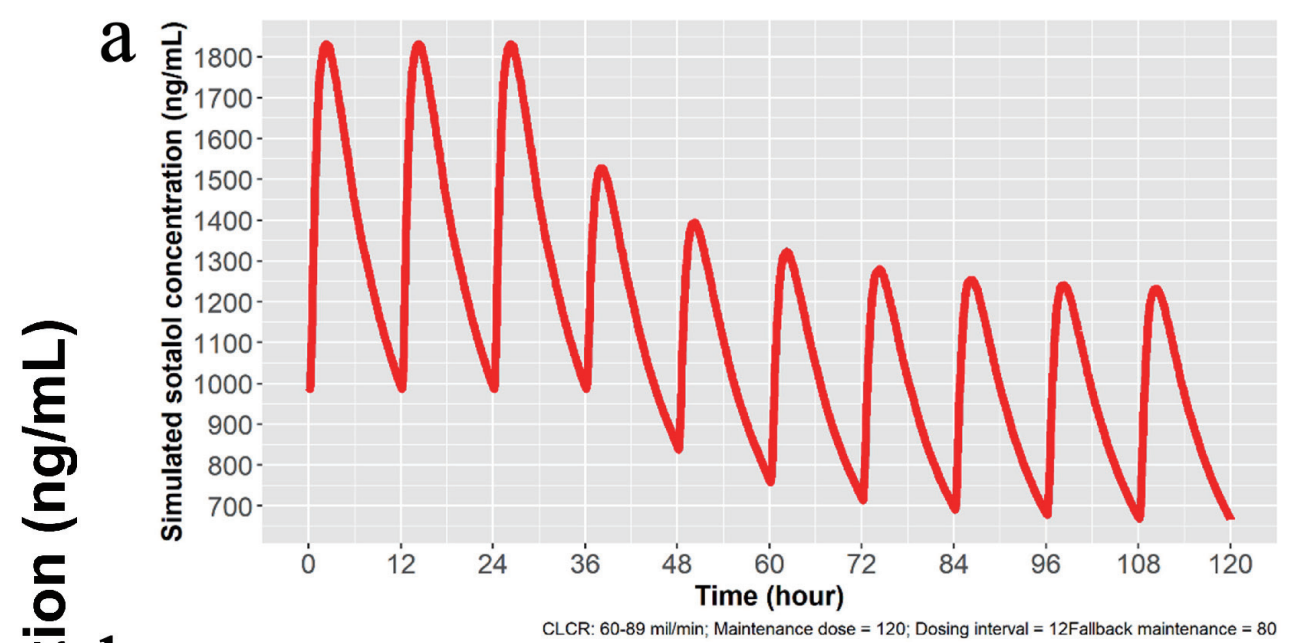

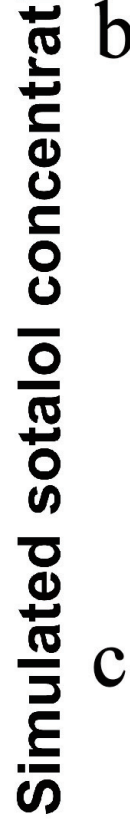
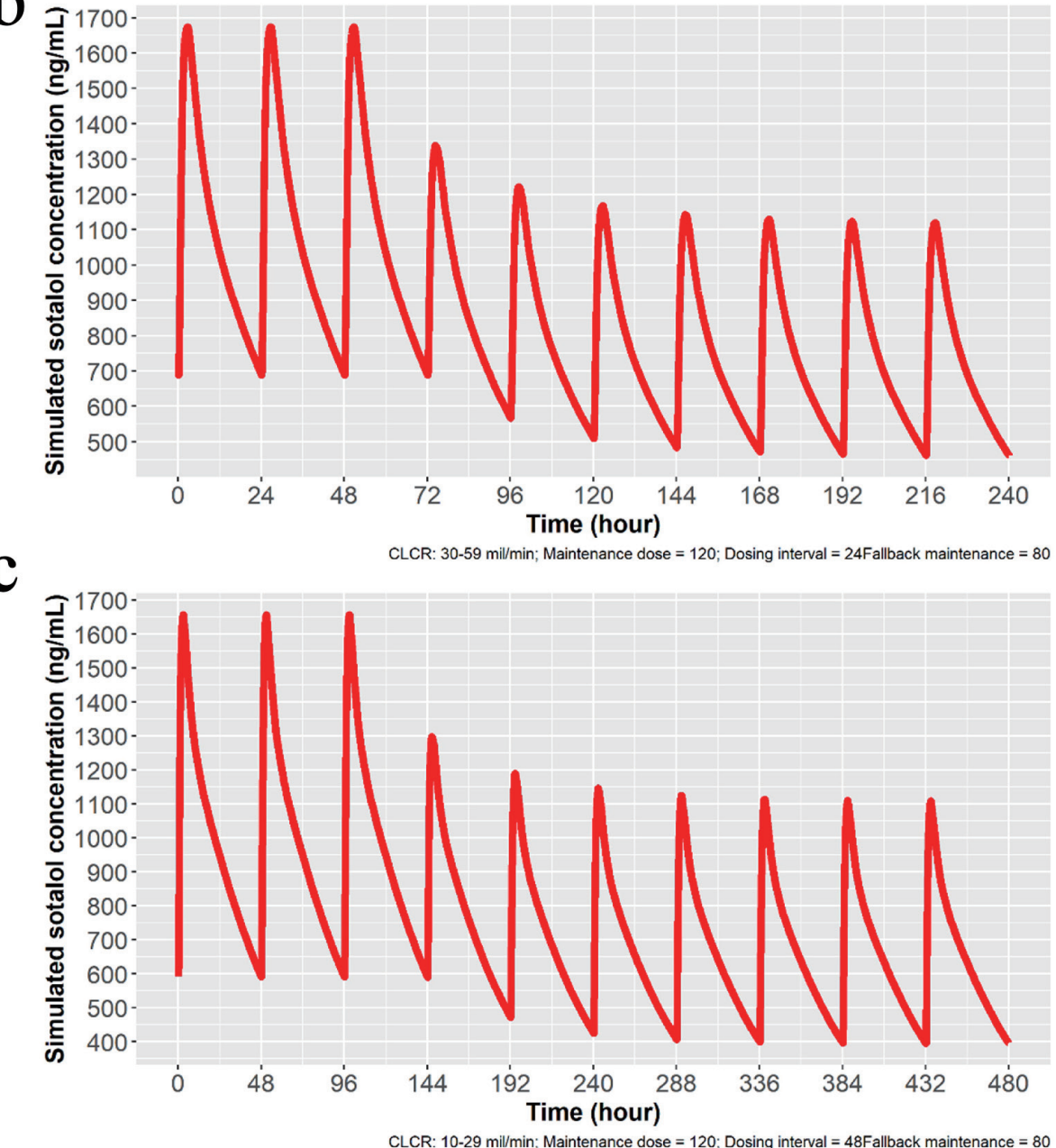

Figure 9. Simulation for dose reduction from 120 to $80 \mathrm{mg} \mathrm{PO}$ sotalol for patients with mild, moderate and severe impairment of renal function. (a) Simulation for patients with mild renal impairment (CICr: $60-89 \mathrm{~mL} / \mathrm{min})$. After the last $120 \mathrm{mg}$ dose, $80 \mathrm{mg}$ is given in $12 \mathrm{~h}$, and a new steady state is achieved in $48 \mathrm{~h}$, with $80 \mathrm{mg}$ dosing every $24 \mathrm{~h}$ thereafter. (b) Simulation for patients with moderate renal impairment (CICr: $30-59 \mathrm{~mL} / \mathrm{min}$ ). Twenty-four hours after the last $120 \mathrm{mg}$ dose, $80 \mathrm{mg}$ is given and new steady state is reached in $72 \mathrm{~h}$ with $80 \mathrm{mg}$ dosing every $24 \mathrm{~h}$. (c) Simulation for patients with severe renal impairment (CICr: $10-29 \mathrm{~mL} /$ $\mathrm{min}$ ). Forty-eight hours after stopping the last dose of $120 \mathrm{mg}$, a dose of $80 \mathrm{mg}$ is given and a new steady state is obtained in 96 $\mathrm{h}$, with $80 \mathrm{mg}$ dosing every $48 \mathrm{~h}$ thereafter. ClCr: creatinine clearance; PO: oral; 
med/drugInfo.cfm?setid=ff3061ab-d930-4318-a5be684e38be229e.

5. MacNeil DJ, Davies RO, Deitchman D. Clinical safety profile of sotalol in the treatment of arrhythmias. Am J Cardiol. 1993;72(4):44A-50A.

6. Bunch TJ, May H, Bair T, Steinberg BA, Muhlestein JB, Anderson JL, Knowlton K. Economics of sotalol in-patient dosing approaches in patients with atrial fibrillation. JACC. 2020;75(Suppl1):e362.

7. Somberg JC, Preston RA, Ranade V, Molnar J. Developing a safe intravenous sotalol dosing regimen. Am J Ther. 2010;17(4):365-372.

8. Dong M, Fukuda T, Selim S, Smith MA, RabinovichGuilatt L, Cassella JV, Vinks AA. Clinical trial simulations and pharmacometric analysis in pediatrics: application to inhaled loxapine in children and adolescents. Clin Pharmacokinet. 2017;56(10):1207-1217.

9. Hanyok JJ. Clinical pharmacokinetics of sotalol.
Am J Cardiol. 1993;72(4):19A-26A.

10. Antonaccio MJ, Gomoll A. Pharmacology, pharmacodynamics and pharmacokinetics of sotalol. Am J Cardiol. 1990;65(2):12A-21A; discussion 35A-36A.

11. Sotalol hydrochloride tablet prescribing information. Available at: https://dailymed.nlm.nih.gov/daily$\mathrm{med} /$ drugInfo.cfm?setid=62a71 c8c-d92d-4122-848f$9 a e 35$ f 8 bbe $2 b$.

12. Somberg JC, Preston RA, Ranade V, Molnar J. QT prolongation and serum sotalol concentration are highly correlated following intravenous and oral sotalol. Cardiology. 2010;116(3):219-225.

13. Benditt DG, Williams JH, Jin J, Deering TF, Zucker R, Browne K, Chang-Sing P, et al. Maintenance of sinus rhythm with oral d,l-sotalol therapy in patients with symptomatic atrial fibrillation and/or atrial flutter. d,lSotalol Atrial Fibrillation/Flutter Study Group. Am J Cardiol. 1999;84(3):270-277. 